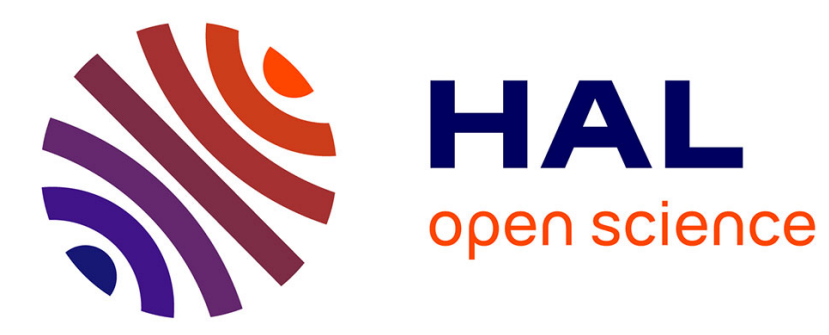

\title{
Maintenance policy: degradation laws versus hidden Markov model availability indicator
}

Pascal Vrignat, Manuel Avila, Florent Duculty, Sébastien Aupetit, Mohamed Slimane, Frédéric Kratz

\section{- To cite this version:}

Pascal Vrignat, Manuel Avila, Florent Duculty, Sébastien Aupetit, Mohamed Slimane, et al.. Maintenance policy: degradation laws versus hidden Markov model availability indicator. Proceedings of the Institution of Mechanical Engineers, Part O: Journal of Risk and Reliability, 2012, 226(2) (1748006X11406335), pp.137-155. hal-00628931

\section{HAL Id: hal-00628931 https://hal.science/hal-00628931}

Submitted on 4 Oct 2011

HAL is a multi-disciplinary open access archive for the deposit and dissemination of scientific research documents, whether they are published or not. The documents may come from teaching and research institutions in France or abroad, or from public or private research centers.
L'archive ouverte pluridisciplinaire HAL, est destinée au dépôt et à la diffusion de documents scientifiques de niveau recherche, publiés ou non, émanant des établissements d'enseignement et de recherche français ou étrangers, des laboratoires publics ou privés. 


\title{
Maintenance policy: degradation laws versus Hidden Markov Model availability indicator
}

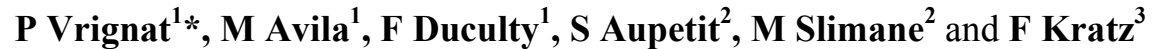 \\ ${ }^{1}$ Orleans University, PRISME Laboratory (EA 4229), Chateauroux, France \\ ${ }^{2}$ François Rabelais University Tours, Laboratory of Computer Sciences (EA2101), Polytech'Tours, Tours, \\ France \\ ${ }^{3}$ ENSI, PRISME Laboratory (EA 4229), MCDS Team, Bourges, France \\ *Corresponding author: PRISME Laboratory, MCDS Team, University of Orleans, 2 av. François Mitterrand 36000 Châteauroux, \\ France.Email: pascal.vrignat@univ-orleans.fr
}

\begin{abstract}
Today, maintenance strategies and their analyses remain a worrying problem for companies. Socio economic stakes depending on competitiveness of each strategy are even more linked to activity and quality of maintenance interventions. A series of specific events can eventually warn the expert of an imminent breakdown. Our study aims at understanding such "signature" thanks to hidden Markov models. On that purpose, two methods for damage level estimation of maintained system are proposed to expert. The first one consists in using a non parametric and semi-parametric degradation laws (which will be used as references). The second one consists in using a markovian approach. All proposals are illustrated on two studies corresponding to two real industrial situations (continuous system for food processing and moulded products in aluminum alloys for the automotive industry).
\end{abstract}

Keywords: diagnosis, maintenance management, assessment, degradation laws, Hidden Markov Model

\section{INTRODUCTION}

Industrial processes need to be maintained to prevent breakdown. Some years ago, maintenance activities were only deployed to repair process after the problem occurs. Nowadays, in an international market context, companies need to improve their productivity. In this context, maintenance strategies are included in reliability engineering. This field includes technological aspects, personal organisation, logistic... Different kinds of maintenance policy can be applied: preventive or corrective according to manager strategies.

In case of preventive maintenance, different strategies should be used like planned preventive maintenance or condition-based maintenance. Planned actions would be program using feedback from experience which used statistical frequencies of defaults. Condition-based maintenance could use specific features extracted from the process like vibration sensors, oil analysers... Then according to these indicators, maintenance actions can be performed. In many cases, defaults are preceded by specific series of events. Black smoke behind a car informs that engine could stop. Dark clouds indicate it will rain... Events which precede default could inform about imminence of it.

Valdez-Florez et al., [44] survey researches on model optimization for repair, replacement, and inspection of systems subject to stochastic deterioration. Simeu-Abazi et al., [41] adopted a modular modelling approach, based on a cellular decomposition of the system. They use stochastic Petri nets and Markov chains to implement various maintenance strategies in complex production workshops. A parametric decision framework (multi- 
threshold policy) is proposed to choose sequentially the best maintenance actions and to schedule future inspections, using on-line monitoring information on the system deterioration level [17], [25]. Deterioration of technical systems can often be classified into discrete states, and transitions between these states can be modelled using a Markov process. Instead of using an exponential distribution, it may be more realistic to assume that a general probability distribution describes staying time in one of these states [49]. Soro et al., [42] proposed a model for evaluating availability, production rate and reliability function of multi-state degraded systems subject to minimal repairs and imperfect preventive maintenance. System status is considered to degrade with its use. These degradations may decrease system efficiency. It is assumed that the system can consecutively degrade into several discrete states, which are characterized by different performance rates, ranging from perfect functioning towards complete failure. Nevertheless, global performances are difficult to be controlled because system environment changes. Functioning modes are dependent on product flows, and ageing of components modifies continuously system characteristics. Thus today, most maintenance strategies are not well adapted to these requirements because purely reactive (fixing or replacing equipment after it fails) or time-scheduled [48]. As in these studies, we show that a degradation level of a process can be proposed to the expert (maintenance manager), from series of "field" events. In this study, we try to learn, without "a priori", this default signature. The originality of our work, is to use the maintenance activities as indicators (Fig. 1 and Fig. 2). Works presented in this paper take part of condition monitoring systems. Using observations provided by the process, we try to generate an availability indicator which can be used by maintenance manager to plan actions dynamically (Fig. 1 and Fig. 2). According to system availability, preventive maintenance could be scheduled to prevent uncontrolled stops of system.

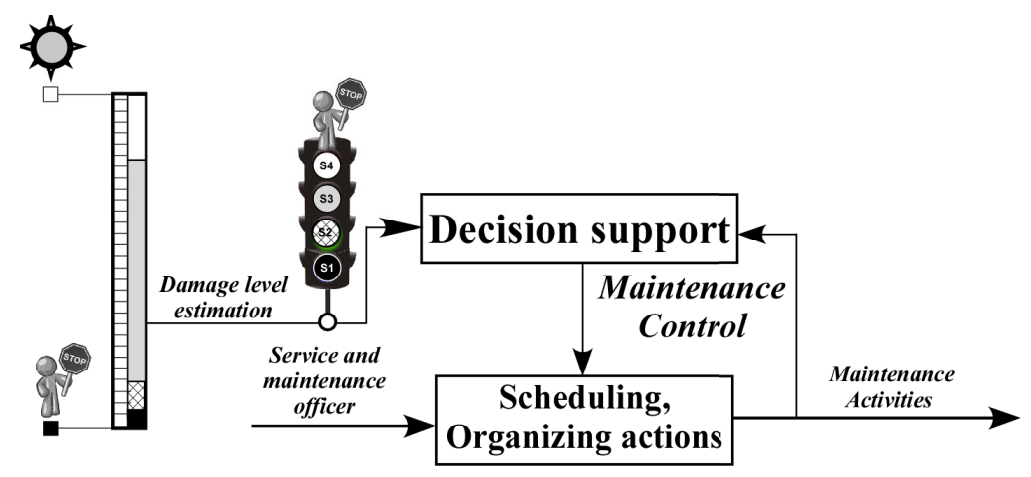

Fig. 1 Work goals

Hidden Markov Models (HMM) have been used, with success, to model sequences of events like, for example, in speech recognition. To improve results of these methods, model parameters should be adjusted to match event characteristics (states, topology ...). In this study, we use the same strategy to learn events which can be observed on an industrial process. Model topology is configured to provide an availability explanation to our model. When system is started, model will indicate a high level of availability. When system is stopped by defaults, model will be in the "off" state (red state: it is too late to prevent default). Our new estimator is compared with "classical" degradation laws. These degradation laws are used as references.

In the next part, we introduce maintenance strategies and our works are located in this context. In part 3 , we recall some "classical" reliabilities laws. We give more details for Kaplan-Meier law and Cox model, which have been implemented. In part 4, our strategy to use HMM for availability indicator implementation is presented. In the last part, we compare results of "classical" degradation laws with our HMM availability indicator on two studies: a continuous food process and an aluminum alloys process for the automotive industry. 


\section{MAINTENANCE POLICIES}

Maintenance strategy is a part of reliability engineering. Reliability is the ability of a system to perform its goals or functions. This can include technology, strategy, finance and humans [18]. Others explanations of maintenance should be find in [24] and [43]. In an international market context, maintenance strategies need to be improved with production tools being even more complex. Between the 40's, maintenance has grown between corrective actions towards predictive system which try to prevent failures [36].

Maintenance is defined by norm N. F. E. N. 13-306 [1]. It can be detailed as a list of actions which enables to a system or a service to perform its goals. In [39] authors split maintenance into two kinds of activities: technical activities and management activities. More details can be found in [50].

Fig. 2. shows different kinds of maintenance policies. This figure shows two keywords of maintenance definition: preventive and corrective. A review of different maintenance strategies can be found in [10] and [22]. In some specific cases, maintenance policy could be imposed, like it is the case for nuclear plant in France.

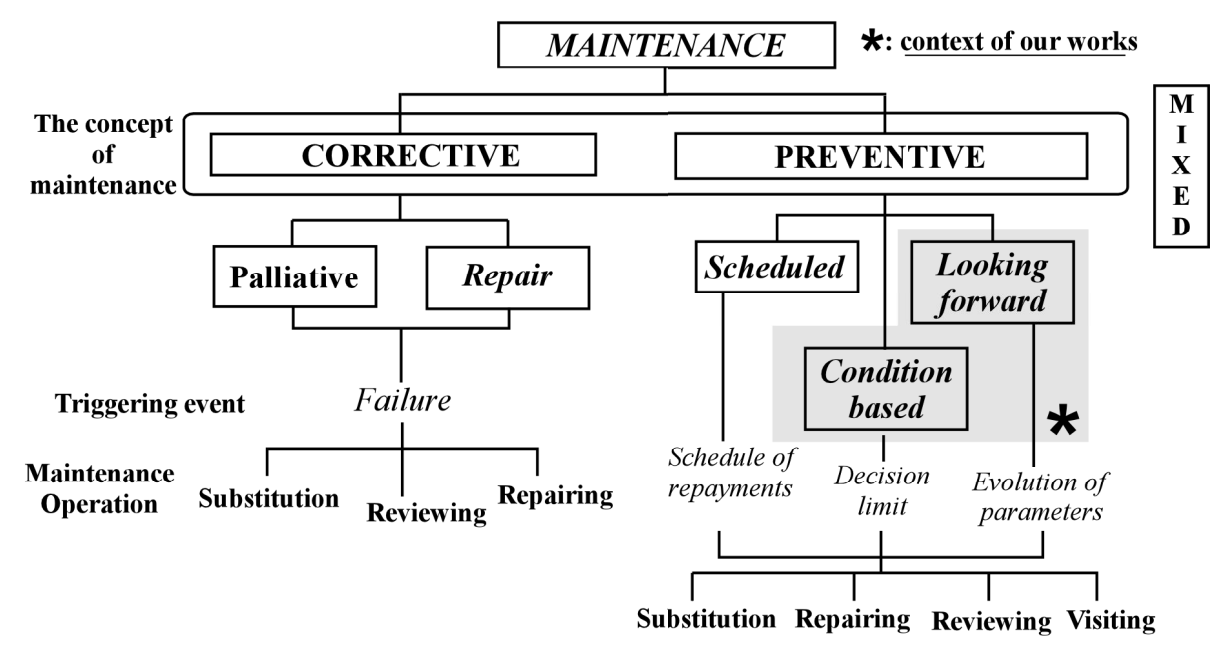

Fig. 2 Maintenance policies

We do not give details about corrective maintenance. The aim of the proposed method is to prevent failure to occur. It could be used to adjust preventive maintenance. This kind of maintenance can be applied by different ways and it is composed of:

- various tasks on systems, monitoring, calibration, ... It also includes lubrication and oil changes in order to reduce friction, wear, prevent galling and save energy.

- Auto-maintenance tasks by the operator. This kind of actions is included in Total Productive Maintenance (TPM) where machine operator performs much, and sometimes all, of routine maintenance tasks.

- Planned maintenance which is scheduled according to time or cycle. Visual inspection can be made or subsystems can be dismantled to inspect themes with accuracy. Tasks like calibration, cleaning, lubrication ... can be planned according to lifetime duration of parts.

- Systematic replacement based on time or cycles. This supposes an accurate counter of time or cycles and correct information about component lifetime. These parts should be systematically replaced. 
- Condition-based maintenance uses particular information provided by sensors with, if necessary, specific signal processing. In this case, failure can be detected before it occurs using feedback from experience.

The replacement of components for which failure is thought to be imminent, can be performed when the component is strongly damaged according to different use criteria, or when it has reached a critical condition. The success of this approach depends on the ability to predict the remaining life of the component and when to perform the replacement [9], [14].

\section{RELIABILITY STUDY OF MAINTAIN PROCESS}

Reliability is often used by maintenance expert. In this section, some usual lifetime laws are presented. These laws can be used as well for medical studies as for industrial context. Main properties of these laws (probability density, reliability functions, failure rate) are defined and applied in reliability applications [27], [12]. Commonly, parametric models and nonparametric models based on proportional risk are used [11]. Different classical laws of degradations exist: exponential law, normal law (Laplace-Gauss), Log-normal law (or Galton law), Weibull. We do not present these laws in this paper.

Efficient maintenance is related to a pertinent estimation of components lifetime. This estimation is based on experience feedback. Lifetime study of each system can be split into two options which need a great analysis of this experience feedback:

- System reliability is its ability to perform what it has to do in its usual conditions during a given time [3], [2]. Reliability expert try to plan new maintenance strategy using reliability evolution.

- Durability is the ability for a system to perform its goals, given using and maintaining conditions, until a limit state is reached [1]. Durability expert tasks should consist in estimation of remaining lifetime of working systems. This kind of study needs to take into account using conditions, parts replacement, to estimate system lifetime.

\subsection{Kaplan-Meier law}

The Kaplan-Meier method, used in cross-disciplinary field ([16], [19]) provides an estimation of survival functions, with not necessarily regular time intervals, instead of actuarial tables ${ }^{1}$. Survival curves can be used to analyse evolution of populations over the time. These techniques (also called product limit estimators) are used for analysis of survival data, whether for persons (e.g. cancer) or products (wear tools resistance). The first type of information is called "event data", while the second is called "censored data".

$\mathrm{S}(t)$ is the survival function. According to datas $\left(y_{1}, \ldots y_{n}\right)$, we can provide unbiased empirical Kaplan-Meier estimator:

$$
S_{n}(t)=\prod_{i \in\{1, \ldots, n\}, y_{i} \leq t}\left(\frac{n-i}{n-i+1}\right)^{\delta_{i}} \quad n \neq i
$$

Where $\delta_{i}=1$ if $y_{i}$ is an uncensored data (0 if censored data). Lo [34] and Bitouzé [13] propose a definition of this estimator for a measure of concentration of according $\mathrm{S}(t)$ to real distribution, in a non-asymptotic context.

\subsection{Cox model}

Cox regression model is an useful method to study impact of variables on survival time of a process [32], of patients [15] (medical study)... It is applied to survival data, i.e., time variables, censored variables and

\footnotetext{
${ }^{1}$ These methods combine observations by random or predefined intervals. It enables to estimate and to obtain a hazard rate representation.
} 
explanatory variables. This model is based on a maximum likelihood estimation, developed by [23]. Principle of Cox model is to link event happening to explanatory variables. For example, in medical field, we try to assess impact of a pre-treatment on the healing time of a patient. Cox model can be compared with classical regression models: events (modelled by date) should be linked with explanatory variables. Specificity of this approach is its ability to assess relationship between hazard and explanatory variables without assumptions on the shape of baseline hazard function. It contains real parameters and unknown functions (hence appearance of semiparametric methods that take into account this double aspect). It is based on the proportional hazards assumption (instantaneous risk of event happening can be written as the product of a function that depends on time and a function that depends only on specimen features). It can be applied to any situation where event duration is studied. Cox is based on the assumption of proportional hazards. In proportional hazard models, the instantaneous risk is written:

$$
h(t \mid z, \theta)=\lim _{d t \rightarrow 0} \frac{1}{\Delta t} P(t<T \leq t+\Delta t \mid T>t, Z=z)=\alpha_{0}(t) f_{\beta}(z)
$$

With: $Z=\left(Z_{1}, \ldots Z_{p}\right)^{T}$ : a vector of covariates, $\alpha_{0}$ : basis risk, unknown, independent of $Z$, $\beta$ : the regression parameter, unknown, $f_{\beta}(z)$ : relative risk, independent of time.

For example: risk ratio for two individuals is independent of time. Regressors $Z_{1}, \ldots Z_{p}$, quantitative or qualitative are called prognostic factors (age, sex, treatment, ...). In the Cox model, the instantaneous risk for an individual $i$ is written:

$$
h\left(t \mid Z_{i}\right)=\alpha_{0}(t) \exp \left(\beta_{1} Z_{i, 1}+\ldots, \beta_{p} Z_{i, p}\right)=\alpha_{0}(t) \exp \left(\beta^{T} Z_{i}\right)
$$

$\alpha_{0}(t)$ is any function which depends only on time (basis risk is unknown and independent of $Z_{i}$ ), and $\beta_{1}$, $\beta_{2}, \ldots \beta_{p}$ are constants with: $\alpha_{0}(t), \quad \beta=\left(\beta_{1}, \ldots \beta_{p}\right)^{T}$ is the unknown regression parameter. With: $Z_{i}=\left(Z_{i, 1}, \ldots Z_{i, p}\right)$ : a vector components. $S_{0}$ is the basic survival function associated with $\alpha_{0}$. In this case, we have the following relationship: $S\left(t \mid Z_{i}\right)=\left[S_{0}(t)\right] \exp \left(\beta^{T} Z_{i}\right)$. This provides an estimate of $S$ knowing $\beta$ the estimation vector. To estimate the components of the vector $\beta$ from an ordered sample $\left(y_{(1)}, \ldots y_{(n)}\right)$, we calculate the partial likelihood function of Cox (if no censored data):

$$
L\left(y_{(1)}, \ldots y_{(n)} ; \beta\right)=\prod_{i=1}^{n} \frac{\exp \left(\beta^{T} Z_{i}\right)}{\sum_{k \in R\left(y_{(i)}\right)} \exp \left(\beta^{T} Z_{k}\right)}
$$

Note:

- $\exp \left(\beta_{i}\right)$ relative rate of subjects for which $X_{j}=1$ compared to those for which $X_{j}=0$,

- $\quad \exp \left(\beta_{i}\right)>1$ : harmful effect $; \exp \left(\beta_{i}\right)=1$ : no effect ; $\exp \left(\beta_{i}\right)<1$ : positive effect.

\section{MODELS OF RELIABILITY BASED ON MAINTENANCE}

Failure of equipment can be characterized by a rate $(\lambda)$ known as failure rate. This rate is also called the failure rate, hazard rate or mortality rate. It is defined as the conditional probability that equipment fails between time $t$ and $\mathrm{t}+\Delta \mathrm{t}$ knowing that it has survived to time $t$. It can also be defined as components proportion that has 
survived until time $t$. It also represents happening failure rate [5], [29]. Variable "time" could be considered as a unit of use. Indeed, in case of some devices, distance travelled, rounds number, requests number... could be considered as "time".

$$
\lambda(t)=\lim _{\Delta t \rightarrow 0}\left(\frac{1}{\Delta t} \frac{R(t)-R(t+\Delta t)}{R(t)}\right)
$$

With:

- $\quad R(t)$ : number of components that have survived until time $t$,

- $\quad R(t+\Delta t)$ : number of components that have survived until time $t+\Delta t$.

This law is based on the fact that evolution of intensity function $\lambda(t)$ is determined by efficiency of maintenance operations. In practice, a maintenance activity is labelled:

- Minimal, if system state after repair is As Bad As Old: $\operatorname{ABAO}(\lambda(\mathrm{t})=\lambda \mathrm{t} ; \forall \mathrm{t} \geq 0)$, (Fig. 3),

- Perfect, if maintenance returns the system As Good As New: AGAN

$\lambda_{t}=\lambda\left(t-T_{N_{t-}}\right)$

with $T_{N t}$ the left limit of stochastic process $N(t)$ ), (Fig. 3). This kind of problem, firstly studied by [28], has been the subject of many developments including several variants, [26], [37], [38],

- Imperfect (Proportional Age Reducing model). In this kind of works, Doyen et al., [26] propose different alternatives to build stochastic models of the process of failures and repairs of various systems. A virtual age model is characterized by a sequence of positive random variables $A=\left\{A_{i}\right\}_{i \geq 0}$ (ages staff) as $A_{0}=0$. These models are based on assumption that after lot of maintenance, system behaves as a new system that would operate for a period $A_{i}$ without fail. $A_{i}$ is virtual age of the system.

$P\left(X_{i+1}>x \mid X_{1}, \ldots, X_{i}, A_{i}\right)=P\left(Y>A_{i}+x \mid Y>A_{i}, A_{i}\right)$

$Y$ is a random variable equally distributed as $X_{1}$.

From this relationship, model intensity can de written as:

$\lambda_{t}(N, A)=\lambda\left(t-T_{N_{t-}}+A_{N_{t-}}\right)$

$t$ is actual age of the system and virtual age, $V(t)=t-T_{N_{t-}}+A_{N_{t-}}$ is related to maintenance interventions. If we compare equations (6), (7) and (8), we find that ABAO model corresponds to $A_{i}=T_{i}$ and AGAN model corresponds to $A_{i}=0$. Baxter et al., [8] propose a simple model to characterize actual age. They assume that effect of the $\mathrm{n}^{\text {th }}$ maintenance is to reduce the virtual age just before failure, $A_{i-1}+X_{i}$ by a proportional amount of time elapsed since previous maintenance $B_{i} X_{i}$, with $B_{i} \in[0,1]$ (equation (9)).

$$
A_{i}=A_{i-1}+\left(1-B_{i}\right) X_{i}
$$

In this relationship, we can deduce easily the recurrence relation: 


$$
A_{i}=\sum_{j=1}^{i}\left(1-B_{j}\right) X_{j}
$$

Related density function on this model is:

$$
\lambda_{t}(N, B)=\lambda\left(t-T_{N_{t-}}+\sum_{j=1}^{N_{t-}}\left(1-B_{j}\right) X_{j}\right)
$$

The most simple model of Kijima [33] is obtained assuming that efficiency of maintenance $B_{i}$ is deterministic, constant and equal to $\rho$, called improvement factor. Taking into account this assumption, the intensity function becomes:

$$
\lambda_{t}=\lambda\left(t-\rho T_{N_{t-}}\right)
$$

Depending on value of $\rho$, we can model any kind of maintenance:

- $\rho=1$ : maintenance is perfect (AGAN),

- $\rho \in] 0,1[$ : maintenance is effective,

- $\rho=0$ : maintenance is minimal (ABAO),

- $\rho<0$ : maintenance is harmful.
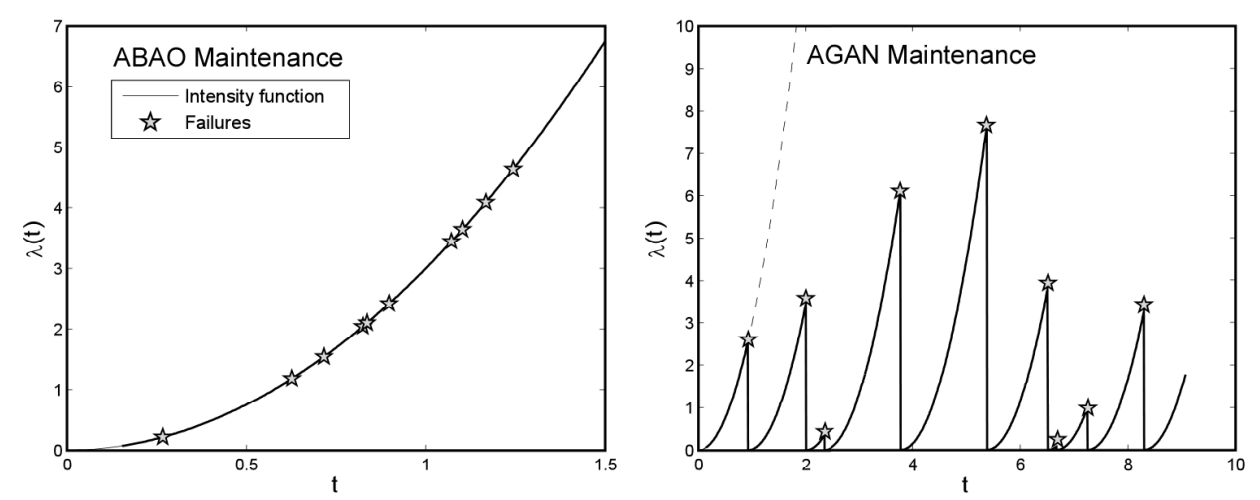

Fig. 3 Intensity functions for ABAO and AGAN maintenance [6]

\section{DECISION SUPPORT BASED ON HIDDEN MARKOV MODELS}

Stochastic models are representations of dynamic systems based on probabilities. Stochastic processes were firstly developped in the early 20th century by a Russian mathematician, Andrei Andreyevich Markov. His statistical study of language has led to the markovian hypothesis, which can be summarized as follows: "Future evolution of a system only depends on its present state". This hypothesis implies that current state of a system contains all information provided by its past. Therefore, it is a very important assumption. In practice, this condition is rarely satisfied. However, approximation by Markovian models could provide good modelling results (Hopp [30] proposes a maintenance model under Markovian deterioration is developed in which maintenance and replacement actions are permitted and states are completely observable). Meier-Hirmer [35] proposes a model used for the maintenance of railway tracks. In this paper, semi-regeneration properties at the 
inspection times and associated Markov renewal techniques are used in order to compute the long-term mean costs.

Risk analysis of dynamical systems by classical markovian approaches considers only two states (On / Failure (Stop)). Between perfect working condition and complete failure state, industrial systems generally have a large set of degraded states in which system continues to provide service, even if it does not produce fully. "These degraded statements need to be taken into account to properly assess service level of industrial systems and this is especially true with regard to production systems [31]".

Hypothesis: events preceding a crash are often recurrent. Specific series of events should inform about the next failure. Some examples can illustrate this hypothesis.

- In mechanical systems, noises, vibrations precede failure. Loss of performances reflects failures or technical defaults,

- In computers, suspect pointer movements, loss of performances, application malfunctions like web browser may reflect virus presence on computer ...

Our approach tries to understand "this signature" using HMM. Hidden process will match system state (or subsystem state) and observations will be observable part of processes (Fig. 4). Our works (Vrignat et al., 2010 ([47])) show that it is possible to model degradation levels of a "continuous" process. Hidden process will fit to system or subsystem states (Run, Degradation level 1, ..., Degradation level N, failure) and observations will be information which can be collected on the system (Fig. 4).

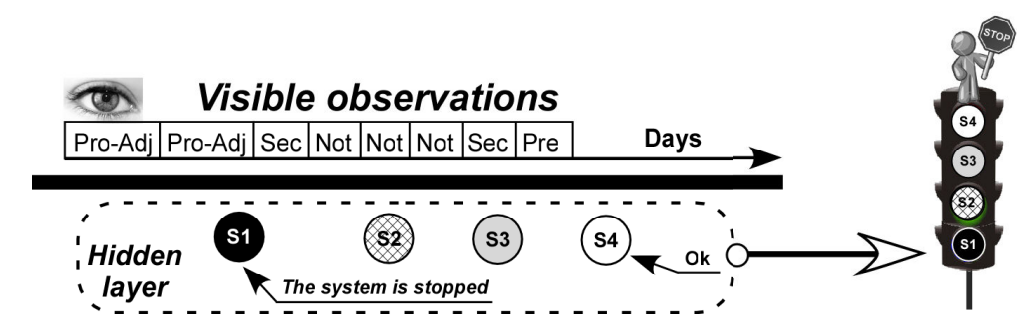

Fig. 4 Visible and hidden layers (system states)

\subsection{HMM Approach}

The aim of this paper is not to present exhaustively Hidden Markov Model. For readers interested in more details, we recommend to read papers [40] (which is already a good tutorial) and [4] which presents HMM general problems. In this paper, we use the same notation for models. A model $\lambda=(A, B, \Pi)$ is described by three matrices:

- $\quad A=\left\{a_{i j}=P\left(S_{j} \mid S_{i}\right)\right\} ; \sum_{j=1}^{N} a_{i j}=1$ corresponding to transition probabilities between hidden states,

- $\quad B=\left\{b_{i}\left(o_{T}\right)=P\left(o_{T} \mid S_{i}\right)\right\} ; \sum_{j=1}^{N} b_{i}\left(o_{j}\right)=1 \quad$ corresponding to probabilities of observations considering states,

- $\quad \Pi=\left\{\pi_{i}=P\left(S_{i}\right)\right\} ; \sum_{i=1}^{N} \pi_{i}=1 \quad$ corresponding to initial state probabilities. 
Learning a hidden Markov model consist in estimating the parameter vector $\lambda$ on the basis of a set of observation sequences. The learning algorithm most commonly used is the Baum-Welch algorithm [7]. This algorithm is derived from the EM algorithm (Expectation-Maximization). The Baum-Welch algorithm solves the problem of learning with the criterion of Maximum Likelihood. For a sequence of observations $O$, this criterion is to find the HMM $\lambda^{*}$ which has the highest probability of generating the sequence $O$ that is to say, maximizing $P(O=O \mid \lambda)$. The Baum-Welch algorithm is a procedure which iteratively re-estimate matrices $A, B$ and $\Pi$ from an initial HMM. The Baum-Welch algorithm provides a local optimum of the likelihood function. By applying this learning with different initial models, it is possible to obtain either a global optimum or a near optimal model for the considered criterion.

Among all the criteria used for learning an HMM, the criterion of segmental K-means is different from others. For this criterion, we seek to maximize the probability $P\left(O, S=Q^{*} \mid \lambda\right)$, with $Q^{*}$ corresponding to the sequence of hidden states that most likely generates the sequence as calculated by the Viterbi algorithm [45]. The segmental k-means algorithm can adjust the model parameters iteratively from an initial model. Just as the Baum-Welch algorithm, this algorithm could provide a local optimum result.

The two previous modes of learning have properties to preserve initial structure of models. When initial model probability is zero then the corresponding probability is zero in the learnt model. It is however important to note that a non-zero probability in the initial model may become zero in the learnt model. This phenomenon often occurs when certain symbols are not observable in learning sequences. A single occurrence of a "missing" symbol in a new sequence will cause non-recognition by the HMM: probability will be zero. To handle this problem, we introduce a smoothing step after the learning step. For each probability, not forced to zero by the model structure an epsilon is added. Constraints of stochastic matrices are obtained by normalizing sums to 1 . This smoothing introduces a distortion of optimal learnt model. We therefore distinguish, in the following, nonsmoothed and smoothed learning.

Once the model is characterized either by the Baum-Welch algorithm or the segmental k-means algorithm, with or without smoothing, we seek to estimate, the most likely sequence of statements on new observations sequences.

For the learning's with the Baum-Welch algorithm, we estimate most probable states at a given time using Forward variables [40]. Let $\alpha_{t}(j)$ be the probability of generating the observation sequence $O=\left\{o_{1}, o_{2}, \ldots, o_{t}\right\}$ and being in state $q_{t}$ at time $t$, that is to say: $\alpha_{t}(j)=P\left(o_{1}, O_{2} \ldots o_{t}, Q_{t}=s_{j} \mid \lambda\right)$. The most probable state at time $t$ is defined by $\operatorname{argmax}_{j=1 . . \mathrm{k}} \alpha_{t}(j)$.

For learnings with the segmental k-means, we consider the most probable state at a given time using the latest state of the optimal path given by Viterbi algorithm [45]. Considering the previous notation, the most probable state is defined by: $\delta_{t}(j)=\max _{q_{1}, \ldots, q_{t-1}} P\left(Q_{1}=q_{1}, \ldots, Q_{t-1}=q_{t-1}, Q_{t}=S_{j}, o_{1}, \ldots, o_{t} / \lambda\right)$.

\subsection{Choice of topology}

Before describing results of our tests, we need to argue the choice of topologies: How many significant and interpretable levels of vigilance can be chosen? In several fields, customs and practices use four vigilance levels:

- prevention policy of flood risk [20], anti-terrorist security plan [21], deterioration and maintenance models for components in hydropower plants [49], ...

For example, for flood risk [20], four vigilance levels are used:

- Green: no particular vigilance is required, 
- Yellow: be attentive if practising activities exposed to meteorological risk, keep informed about weather development,

- Orange: be very vigilant; dangerous meteorological phenomena have been forecast,

- Red: Absolute vigilance is required; dangerous and exceptionally intense meteorological phenomena have been forecast.

Only three states model cannot be used. Which sense can be given at the median state? Glass is half full or half empty? We used an oriented topology (Fig. 5) which does not enable to jump one state from right to left (from high level of availability to lower). We need to go through all states (S2 and S3) to go from S4 state (system OK) to S1 state (System stopped). Symbols used are explained in introduction of Section 6. So we need at least four observations to go from S4 to S1. These are the minimum number of events to detect failure. We keep in mind, the sense we wanted to give to different states: S4 "everything is going well, " S3 "it can go, " S2 "things are bad, beware, " S1 "too late". With more states, we reduce sensitivity of our indicator. Then we choose a four states model. Training of our HMM model (Fig. 5) consists in estimating model parameters with a set of observations sequences.

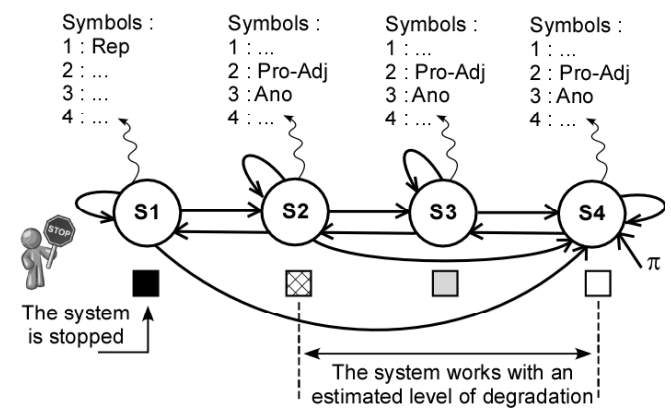

Fig. 5 Oriented topology with 4 states

\section{CASE STUDIES}

\subsection{Industrial baker}

In this part, we present a continuous process of bread production (Fig. 6). Industrial partner, which provide us these data, chose this part of the process because it was the most sensitive part of this production line. This plant works during all year without interruption with teams organized in shift work. For each team, there are available and informed databases in accordance with operational maintenance activities describes for the organization of the continuous process (Table 1). All details and simulations are presented in [46].

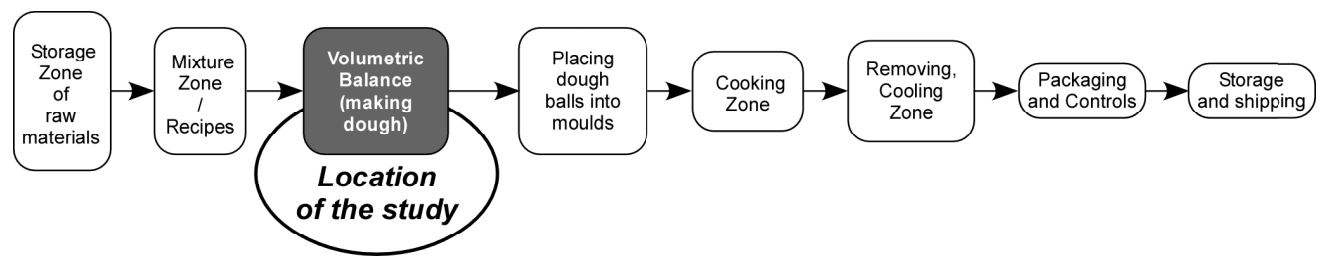

Fig. 6 Bakery continuous process 
Entire production line can be stopped by a failure occurring on one of the subsystems of the line. Such situations could involve a loss of several production hours (some hundred $\mathrm{kg}$ of bakery products). To prevent such cases, preventive maintenance is scheduled. We have access to about two years of recording - from January 2005 to March 2007 - which represent about a thousand of events (Table 1). Model was trained using the "20052006" recording database (611 production records) while data of the year 2007 are used for our different tests.

The chosen sample time was the day (according to internal maintenance policy). To complete the data, a "Not" code stacking interventions was added when maintenance department was not requested (Fig. 7 (b)). Fig. 7 (a) lists different events that could be observed on recordings. Each of them is explained in the table. Some events can be grouped: maintenance actions (Pro-Adj, Pre, Pre-visit, Dis and Mak); observing actions (Obs, Ano, Sec); repairing action (Rep which means system is stopped); no action (Not).

Table 1 Example of logging events

\begin{tabular}{|c|c|c|c|c|c|c|c|c|c|c|c|}
\hline $\begin{array}{c}\text { Number } \\
\text { in the } \\
\text { list }\end{array}$ & NAME & TEAM & DATE & LINE & $\begin{array}{c}\text { NAME OF } \\
\text { THE } \\
\text { MACHINE }\end{array}$ & $\begin{array}{c}\text { CODING } \\
\text { WORK } \\
\text { PERFORMED }\end{array}$ & $\begin{array}{c}\text { OF THE } \\
\text { OBS }\end{array}$ & $\begin{array}{c}\text { MAINTENANCE } \\
\text { ACTIVITIES }\end{array}$ & TI (min) & $\begin{array}{c}\text { PARTS } \\
\text { CHANGED }\end{array}$ & REF \\
\hline 1 & M.Dupond & PM & $03 / 01 / 2005$ & M2 & Balance & $\begin{array}{c}\text { The incharge } \\
\text { request }\end{array}$ & & Pro-Adj & 20 & & \\
\hline 2 & M.Dupond & PM & $03 / 01 / 2005$ & M2 & Balance & $\begin{array}{c}\text { Regulate } \\
\text { the cadence }\end{array}$ & & Pro-Adj & 20 & & \\
\hline
\end{tabular}

Table 2 is a sample of information collected during maintenance activities on the selected period (full uncensored data). From these data, we conducted a descriptive statistical study on subsystem. Definitions of headers of Table 2 are: CASE: repair situations, D_Not: production date OK, D_Rep: onset date of "Repair" situation, J_Rep: situation between two repairs (day), T_xxx (time spent in the activity in minutes) with xxx: Rep, Pro_Adj, Ano, Obs, Pre, Sec, Dis, Mak, Pre-visit, J_Not: time spent in Nothing (day), Time: month in year (month).

Table 2 Review of information related to maintenance activities in database

\begin{tabular}{|c|c|c|c|c|c|c|c|c|c|c|c|c|c|c|c|}
\hline NUM & CASE & D_Not & D_Rep & J_Rep & T_Rep & T_Pro_Adj & T_Ano & T_Obs & T_Pre & T_Sec & T_Dis & T_Mak & T_Pre-visit & J_Not & Time \\
\hline 1 & Rep1 & $03 / 01 / 2005$ & $18 / 01 / 2005$ & 15 & 40 & 40 & 0 & 0 & 60 & 70 & 0 & 0 & 120 & 8 & JAN \\
\hline 2 & Rep2 & $18 / 01 / 2005$ & $24 / 01 / 2005$ & 6 & 40 & 20 & 0 & 0 & 0 & 50 & 0 & 0 & 0 & 5 & JAN \\
\hline
\end{tabular}

In our study of the system (sections 6.3 and 6.4), we consider situations where the volumetric balance was being repaired (no censure is adopted in data processing). After a descriptive analysis of the volumetric balance lifetimes, we will study the nonparametric and semi-parametric estimates of its reliability. Only operating periods were taken into account to study balance lifetime. Average duration between two "Repair" situations (system being stopped) estimated on database is 5.38 days. It includes, between two "Repair" situations, all other possible operational maintenance activities respecting internal symbolic coding. (Pro_Adj, Ano, Obs, Pre, Sec ... (Fig. 7(a)). 


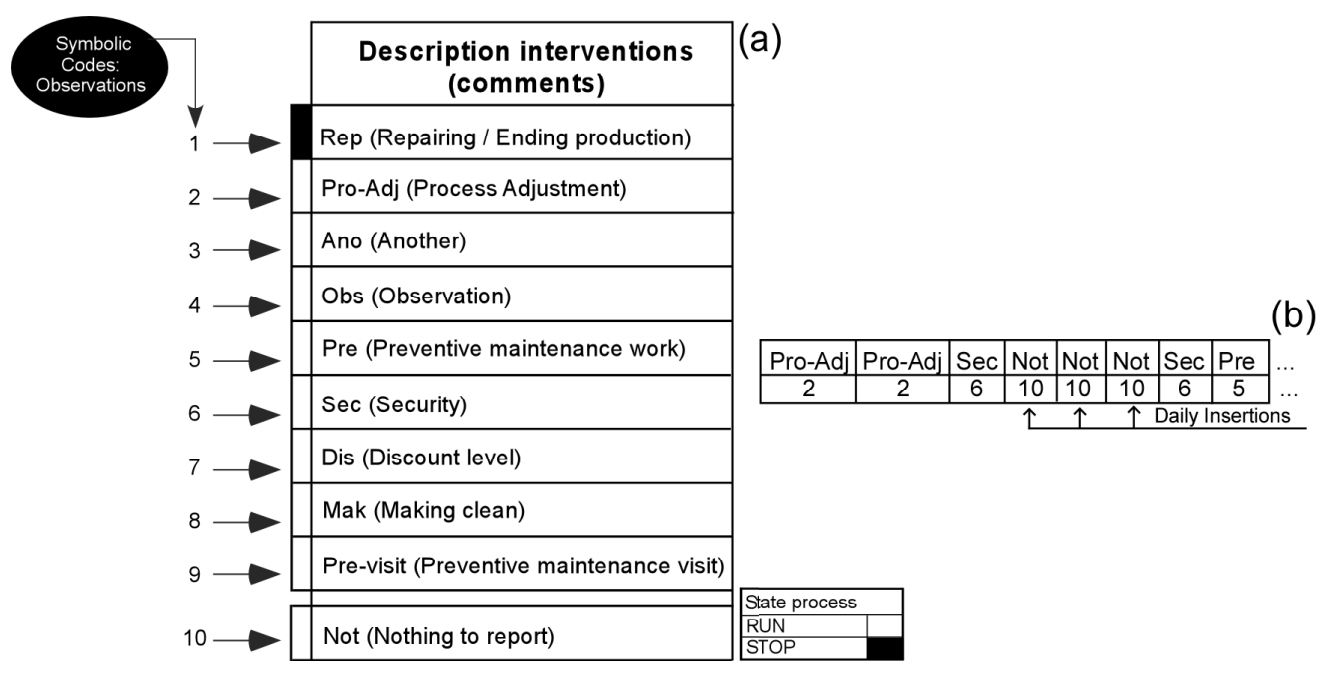

Fig. 7 (a): Symbolic coding of observations. (b): coding principle of observations sequence with "Not" insertion

In order to provide a daily evaluation by our indicator, we insert a specific symbol Not (Nothing to report) every day when no event is recorded (Fig. 7 (b)). If more than one symbol is observed during a day, it means that estimated state can change several times in the same day and consequently it increases sensibility of our indicator.

\subsection{Foundry: new approach including Total Productive Maintenance framework}

Fig. 8 shows this new approach including TPM activities.

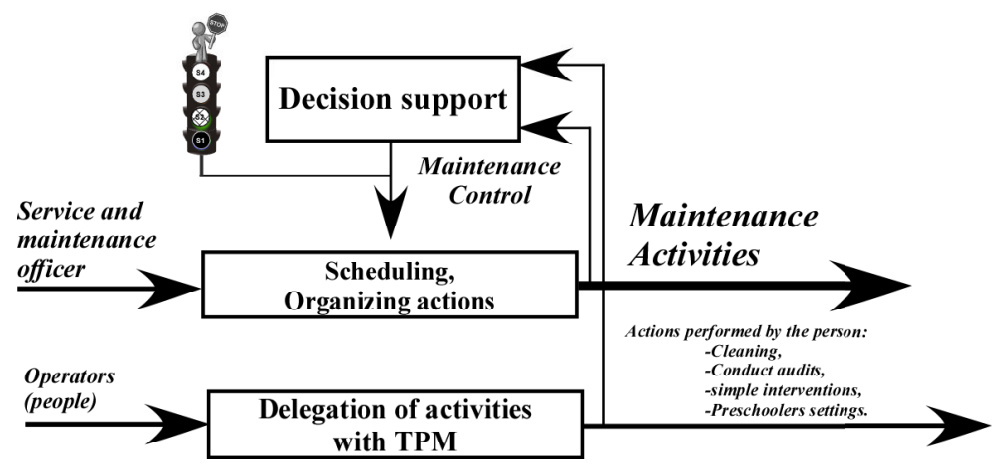

Fig. 8 Approach including TPM

The French industrial group is specialized in moulded products in aluminium alloys. Studied process, is a part of aluminium spares parts manufacturing (Fig. 9 (a) and (b)). 
(a)

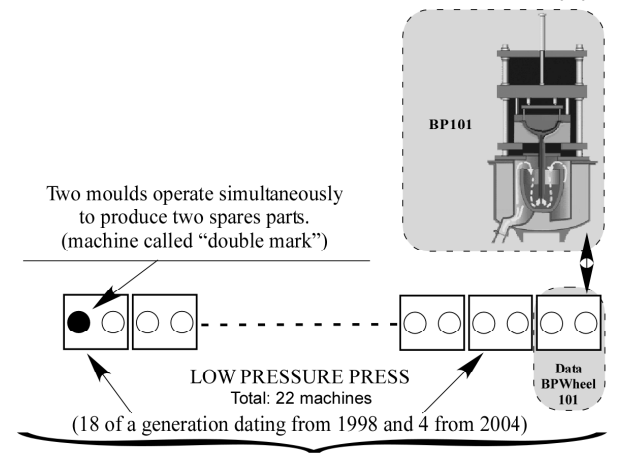

(b)

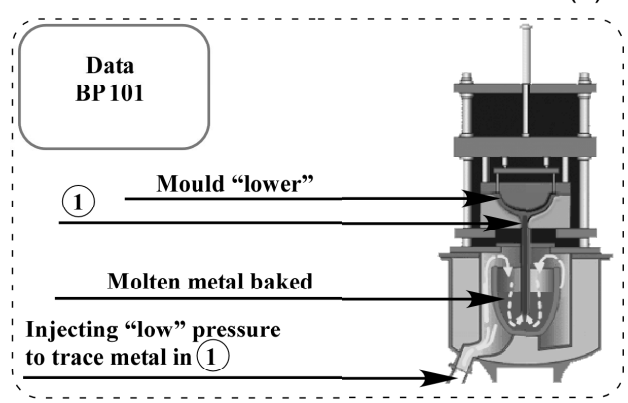

Fig. 9 Process description

The process involves filling piece with low pressure system. Operating principle of low pressure machine is based on four main elements:

- airtight oven to be under pressure,

- supply system between oven and mould,

- system controlling and supporting mould elements,

- mould.

Metal casting principle under low pressure consists in applying low pressure from 0.2 to 2 bar in airtight oven. This pressure can pull the liquid metal up to the mould. Liquid metal gets into link tubes before filling mould. Metal pressure extracts air out of the mould. Main advantage of low pressure process is that the filling method, which in a slow and down to up process, preserves alloy quality. Solidification naturally spreads from cold spots to hot zones. When the part is solidified, pressure is released from the oven and metal which remained liquid returns in the oven, thus separating part from supply system. This process is maintained by a maintenance service and by delegation of small tasks performed by operators according to TPM framework. This system works during all day teams organized in shift work. Our first task was to create database from all operator actions which were recorded on paper.

Table 3 Database samples

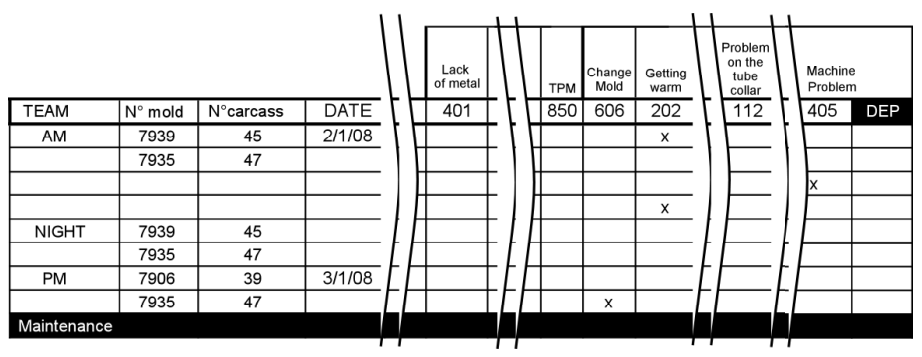

These datas, collected over six months, represent 2218 production records (Table 3). New codification is represented in Fig. 10 (a). Table 3 is a sample of informations collected during maintenance activities on the selected period (full uncensored data). From these datas, we conducted a descriptive statistical study. Definitions 
of Table 4 headers are: CASE: repair situations, D_Not: production date OK, D_Rep: onset date of a "Repair" situation, J_Rep: situation between two repairs (day), T_xxx (time spent in the activity in minutes) with xxx: Rep, LC, CL, ... No, Time: month in year (month).

Table 4 Review of informations relating to maintenance activities in the database

\begin{tabular}{|c|c|c|c|c|c|c|c|c|c|c|c|c|c|c|c|c|c|c|c|c|c|c|c|c|}
\hline NUM & CASE & D_Not & D_Rep & J_Rep & T_Rep & T_LC & T_CL & T_BLC & T_CM & T_GW & T_B & T_S & T_N & T_J & T_TP & T_MP & T_RP & T_OP & T_M & T_Re & T_Pre & T_Not & T_No & Time \\
\hline 1 & Rep1 & $02 / 01 / 08$ & $03 / 01 / 08$ & 1 & 30 & 0 & 0 & 0 & 90 & 190 & 0 & 25 & 0 & 0 & 120 & 105 & 0 & 45 & 0 & 0 & 0 & 0 & 0 & JAN \\
\hline 2 & Rep2 & $03 / 01 / 08$ & $04 / 01 / 08$ & 1 & 90 & 0 & $\overline{0}$ & 0 & 0 & 100 & 0 & 40 & 0 & 0 & 0 & 30 & 0 & 0 & 0 & 0 & 0 & 240 & 0 & JAN \\
\hline 3 & Rep3 & $04 / 01 / 08$ & \begin{tabular}{|l|}
$06 / 01 / 08$ \\
\end{tabular} & 2 & 60 & 0 & 0 & 0 & 0 & 260 & 0 & 115 & 0 & 0 & 0 & 0 & 0 & 0 & 0 & 0 & 0 & 240 & 240 & JAN \\
\hline
\end{tabular}

In our study of lifetime system (sections 6.3 and 6.4), we consider situations where low pressure press was repaired (data are not censored). After a descriptive analysis of low pressure press lifetimes, we will study nonparametric and semi-parametric estimations of its reliability. Only operating periods were taken into account to study low pressure press. Average duration between two "Repair" situations (system is stopped) calculated on database is 3.05 days. It includes, between two "Repair" situations all other possible activities of operational maintenance respecting internal symbolic coding (LC, CL, BLC ..., (Fig. 10 (a)).

Like to the first process, symbol "Not" (Nothing to report) and No (No production) are inserted at least each eight hours when no event is recorded (Fig. 10 (b)). This sampling provides to estimate changes at least every eight hours or more times if more symbols are observed.

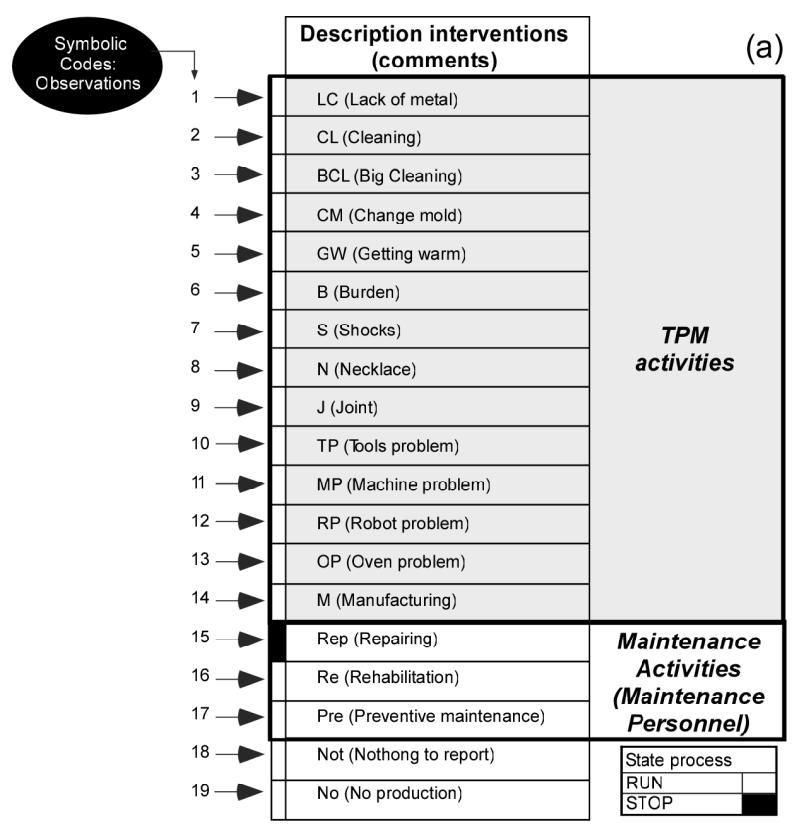

(b)

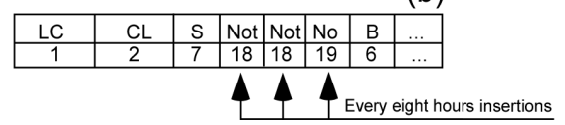

Fig. 10 (a): Symbolic coding of observations. (b): coding principle of observations sequence with "Not" and "no" insertion

\subsection{Kaplan-Meier law applied on systems}

Fig. 11 gives cumulative survival function with a confidence coefficient interval set at 95\%. With this approach, the expert has evidence which indicates that degradation of system is fast (Fig. 11). For bakery continuous process studied, we find that after four days without breakdown, failure rate is up to 50\% (median estimation Fig. $11(\mathrm{a}))$. 
In the case of low pressure press, we see that after two days without breakdown, failure rate is up to $53 \%$ chance (median estimation Fig. 11 (b)). Low pressure press process deteriorates faster than bakery continuous process previously studied.
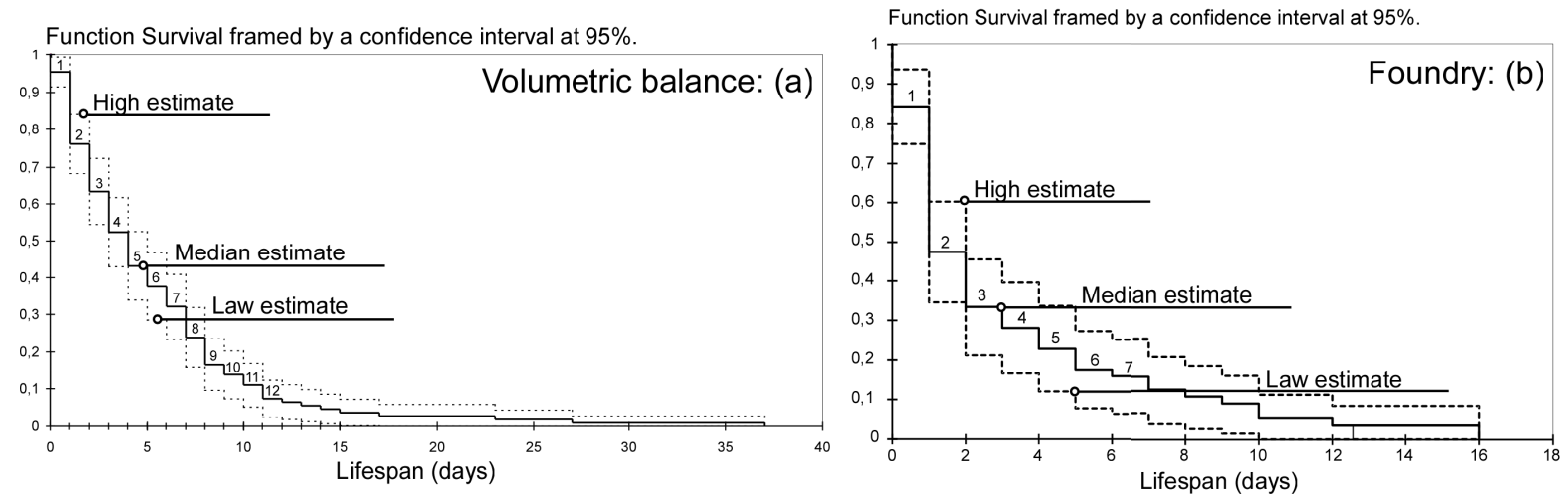

Fig. 11 Survival Functions by Kaplan-Meier

\subsection{Cox law applied on systems}

Proposed values in column "value" are numerical estimations of Cox model parameters. $P_{r}>\chi^{2}$ is a p-value for testing the null hypothesis $\mathrm{H}_{0}$ (parameter $=0$ ). If this p-value is smaller than 0.05 (less than 1 in 20 chance of being wrong), then parameter will be significantly different from 0 . This test $\left(P_{r}>\chi^{2}\right)$ is the threshold to reject the null hypothesis $\mathrm{H}_{0}$.

This value is defined in one hand by the Wald statistic (computed for each variable) and on the other hand by the critical value of $\mathrm{Khi}^{2}$. Values $\exp \left(\beta_{i}\right)$ are placed in column "Report risk, Report risk lower bound and Upper bound". Table 5 (a) shows that only variable T_SEC has an impact on survival time of process (time between two situations of repair). Coefficient $\exp \left(\beta_{i}\right)$, for the Report risk Upper bound (95\%) is the only one $<1$ associated with term $\left(P_{r}>\chi^{2}\right)<0,0001$. We can conclude that more time spent in maintenance activity linked to security (SEC Code) will be "significant" for longer survival time.

According to values $\exp \left(\beta_{i}\right)$ of Table 5 (b), there is no event (maintenance activities) that affects survival time of system. Unlike study on volumetric balance, the expert does not have additional elements to help him.

Table 5 Regression coefficients of the proportional hazards: Cox model

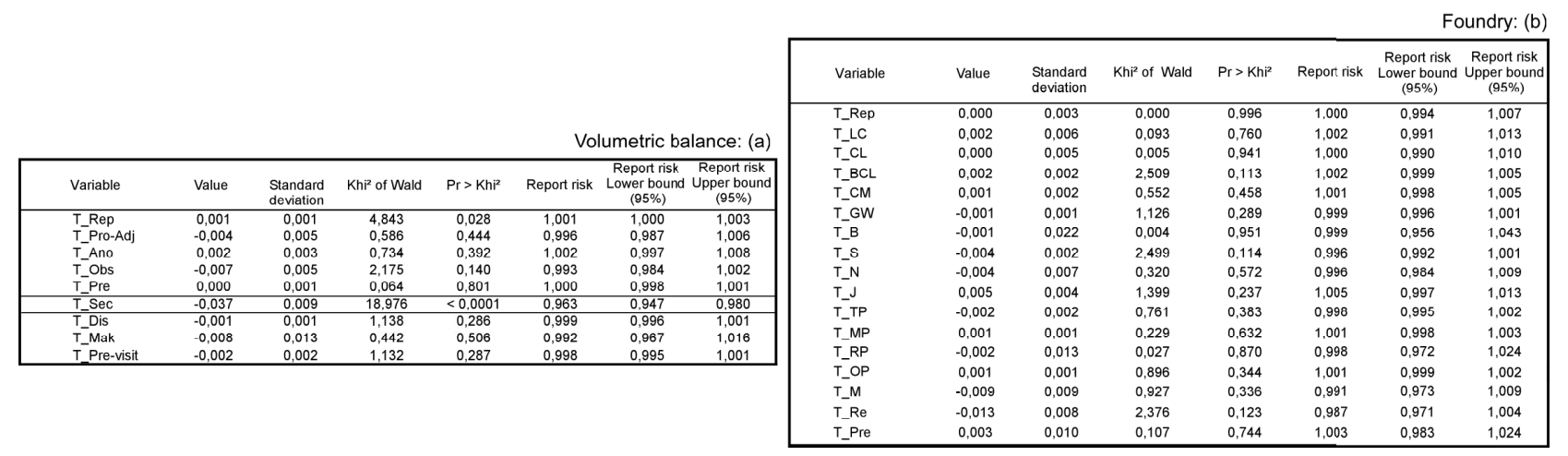


Fig. 12 describes cumulative survival function which takes into account explanatory variables. We can show that results of Cox tests provide more pessimistic values than survival function of Kaplan-Meier tests.
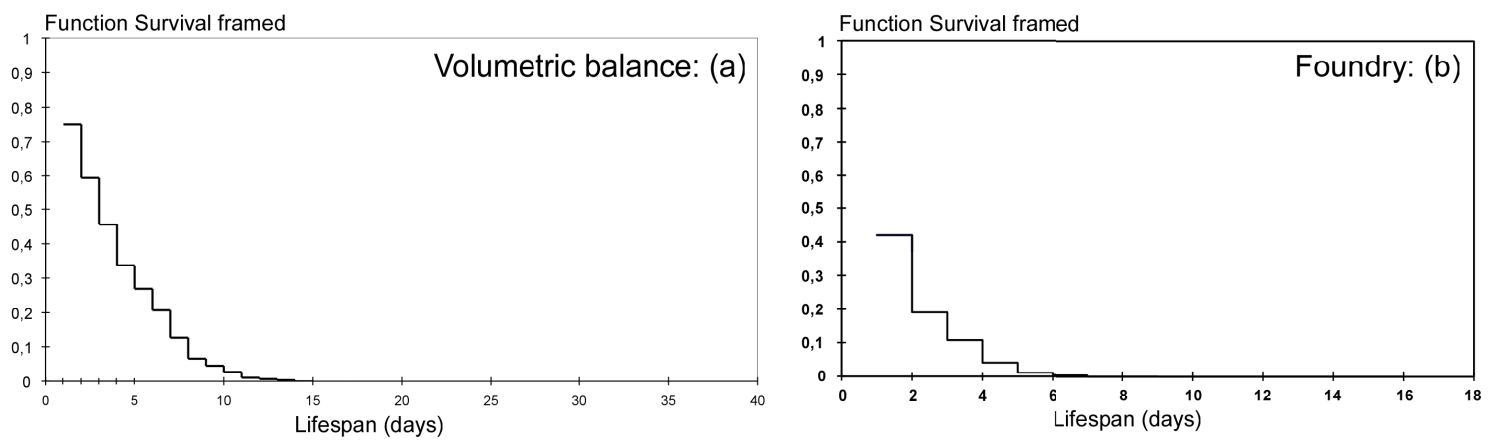

Fig. 12 Survival function estimator by Cox

Table 6 gives an overview of failure rate evolution according to time. From this first approach, the expert can adjust its level of vigilance and decide whether or not maintenance actions based on its return from experience and probability of failure between the last repair situations. Volumetric balance deteriorates slowly than BP Wheel.

Table 6 Failure probability for the two industrial systems

\begin{tabular}{|c|c|c|c|c|c|c|c|c|c|c|c|c|c|}
\hline \multirow{2}{*}{\multicolumn{2}{|c|}{$\begin{array}{l}\text { Volumetric } \\
\text { balance: (a) }\end{array}$}} & \multicolumn{12}{|c|}{ Probability of failure in different tests for the corpus of data for 2005 and 2006} \\
\hline & & at +1 day & $t+2$ days & at +3 days $\mathrm{a}$ & 14 days & at 15 days & at +6 days: & at 17 days a & at 18 days a & at 19 days: & at +10 days & at +11 days & at +12 days \\
\hline \multirow{4}{*}{$\begin{array}{c}\text { Function } \\
\text { Survival framed } \\
\text { by a confidence } \\
\text { interval at } 95 \% \text {. } \\
\text { (Kaplan-Meier) }\end{array}$} & \begin{tabular}{|c|} 
High \\
estimate \\
\end{tabular} & $15 \%$ & $27 \%$ & $38 \%$ & $48 \%$ & $53 \%$ & $59 \%$ & $68 \%$ & $76 \%$ & $79 \%$ & $83 \%$ & $88 \%$ & $90 \%$ \\
\hline & $\begin{array}{c}\text { Law } \\
\text { estimate }\end{array}$ & $32 \%$ & $45 \%$ & $57 \%$ & $66 \%$ & $72 \%$ & $76 \%$ & $84 \%$ & $91 \%$ & $93 \%$ & $95 \%$ & $97 \%$ & $98 \%$ \\
\hline & $\begin{array}{l}\text { Median } \\
\text { estimate }\end{array}$ & $23 \%$ & $36 \%$ & $47 \%$ & $57 \%$ & $62 \%$ & $67 \%$ & $76 \%$ & $83 \%$ & $86 \%$ & $89 \%$ & $92 \%$ & $93 \%$ \\
\hline & $\begin{array}{c}\text { cox } \\
\text { test }\end{array}$ & $41 \%$ & $54 \%$ & $66 \%$ & $73 \%$ & $79 \%$ & $87 \%$ & $93 \%$ & $95 \%$ & $97 \%$ & $98 \%$ & $98 \%$ & $99 \%$ \\
\hline
\end{tabular}

\begin{tabular}{|c|c|c|c|c|c|c|c|c|c|c|c|c|c|}
\hline \multirow{2}{*}{\multicolumn{2}{|c|}{ Foundry: (b) }} & \multicolumn{12}{|c|}{ Probability of failure in different tests for the corpus of data (first half 2008) } \\
\hline & & at +1 day & at +2 days & at +3 days & $t+4$ days & at +5 days & at +6 days & at +7 days & at +8 days & at +9 days & al +10 days & at + 11 days & aat +12 days \\
\hline \multirow{4}{*}{$\begin{array}{l}\text { Function } \\
\text { Survival framed } \\
\text { by a confidence } \\
\text { interval at } 95 \% \text {. } \\
\text { (Kaplan-Meier) }\end{array}$} & $\begin{array}{c}\text { High } \\
\text { estimate }\end{array}$ & $40 \%$ & $54 \%$ & $60 \%$ & $66 \%$ & $73 \%$ & $75 \%$ & $79 \%$ & $82 \%$ & $84 \%$ & $89 \%$ & $89 \%$ & $92 \%$ \\
\hline & \begin{tabular}{c|c|} 
Law \\
estimate
\end{tabular} & $66 \%$ & $79 \%$ & $84 \%$ & $88 \%$ & $92 \%$ & $94 \%$ & $96 \%$ & $97 \%$ & $98 \%$ & $100 \%$ & $100 \%$ & $100 \%$ \\
\hline & \begin{tabular}{|l|} 
Median \\
estimate
\end{tabular} & $53 \%$ & $67 \%$ & $72 \%$ & $77 \%$ & $83 \%$ & $84 \%$ & $88 \%$ & $90 \%$ & $91 \%$ & $95 \%$ & $95 \%$ & $97 \%$ \\
\hline & $\begin{array}{l}\text { cox } \\
\text { test }\end{array}$ & $81 \%$ & $89 \%$ & $96 \%$ & $99 \%$ & $100 \%$ & $100 \%$ & $100 \%$ & $100 \%$ & $100 \%$ & $100 \%$ & $100 \%$ & $100 \%$ \\
\hline
\end{tabular}

\subsection{First conclusion}

We show that Kaplan-Meier model and Cox model (two nonparametric and semi-parametric statistical models) can provide help to the expert with a lot of elements. Without "a priori" information on the shape of the survival function, we first estimated the nonparametric model of Kaplan-Meier. Then, to introduce exogenous variables into the model, we studied a semi-parametric model: Cox. These tests show that, into two industrial case studies conducted, these systems needed to be "highly maintained".

However, models of Kaplan-Meier and Cox propose to the expert only two levels to define the system state (Fig. 13). There is no possible additional state and the main indicator is time that happens outside of any possible correlations. 
We show, in case of volumetric balance, that a correlation between time spent in the activity "SEC" and survival time of the process exists. For the volumetric balance, with planning of maintenance activities being carried out by the day, help is provided to the expert for scheduling dynamically maintenance activities.

In case of BP Wheel, unscheduled interventions come "on the fly" through introduction of TPM. An operator can decide to perform tasks for which he is in charge.

Several problems arise:

- Is it possible to add intermediate states between "Stop" and "OK" (Fig. 13)?

- Is it then possible to prevent failure?

- How to choose the good frequency, the good sampling of collected information to estimate level of process degradation?

- Could all the collected information define a possible hidden state on the process?

We present in section 6.6, details of our approach using HMM. We will answer to issues outlined above. The two industrial cases, already presented, will support our various tests.
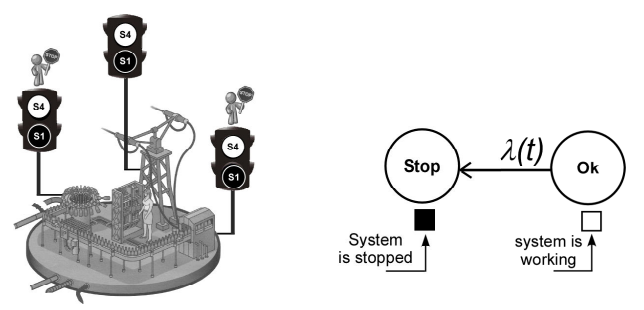

Fig. 13 Models of Kaplan-Meier and Cox associated with two states system

\subsection{Hidden Markov Models applied on systems}

Fig. 14 shows organization of the various tests adopted with four different algorithms. Sampling selected for the volumetric balance is the day (daily insertion of observations). Sampling selected for the BP Wheel is eight hours (shift work).
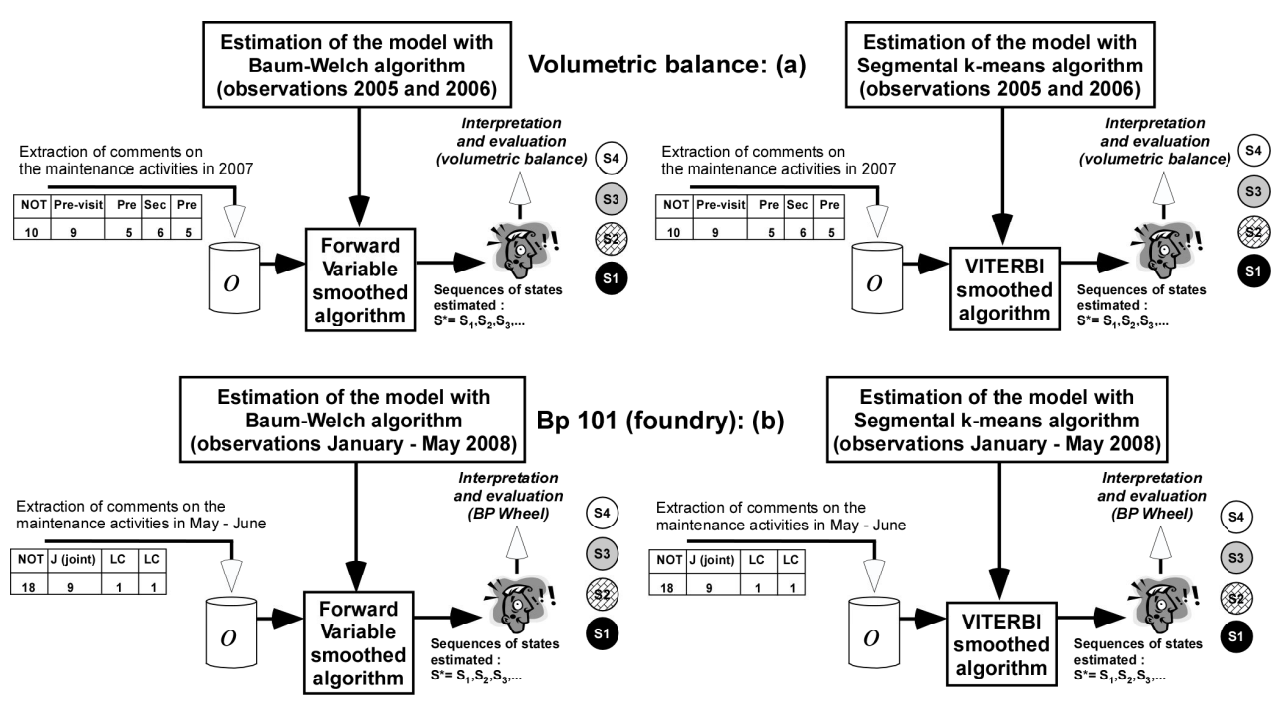

Fig. 14 Methods adopted for different tests 
Our goal is to provide a S2 state which has a "high sense" for preventive maintenance (do not detect default, neither too late nor too early which could provide unnecessary or earlier interventions). Fig. 15 (a) and (b) shows that HMM can provide this kind of detection for S2 state if tools used are correctly chosen. In this figure (Prediction with Forward Variables Smoothed Probability Model / Baum-Welch algorithm), we show, for example, that our approach is efficient considering daily inclusion. S2 state is "on" only 2 days before default occurs. In the same context, with Viterbi algorithm smoothed, we can see that S2 state is on too early. This cannot provide correct clues for optimal planning of maintenance operations. Table 7 and Table 8 summarize results of tests with both algorithms used. In case of volumetric balance, after 3 days, failure is detected in $85.7 \%$ of cases (Table 7 (a)). This statistical information, being only one alone indicator, it can not meet requirements of the expert.

Volumetric balance: (a)

\begin{tabular}{|c|c|c|c|c|c|c|c|}
\hline \multicolumn{4}{|c|}{ Sequence No. $x x x$} & \multicolumn{4}{|c|}{$\begin{array}{l}\text { Prediction Variables Forward With } \\
\text { Smoothed Model probas I } \\
\text { Baum-Welch algorithm }\end{array}$} \\
\hline $\mathrm{n}^{\circ}$ & DATE & CODE & $\begin{array}{l}\text { Symbolic } \\
\text { Codes }\end{array}$ & s1 & s2 & s3 & S4 \\
\hline 1 & \begin{tabular}{|l|}
$09 / 01 / 2007$ \\
\end{tabular} & Not & 10 & $0,0 \%$ & $0,0 \%$ & $0,0 \%$ & $100,0 \%$ \\
\hline 2 & $10 / 01 / 2007$ & Not & 10 & $0,0 \%$ & $0,0 \%$ & $0,1 \%$ & $99,9 \%$ \\
\hline 3 & \begin{tabular}{|l|}
$11 / 01 / 2007$ \\
\end{tabular} & Pre-v & 9 & $0,0 \%$ & $0,0 \%$ & $81,8 \%$ & $18,2 \%$ \\
\hline 4 & \begin{tabular}{|l|}
$11 / 01 / 2007$ \\
\end{tabular} & Pre-v & 9 & $0,0 \%$ & $17,5 \%$ & $79,1 \%$ & $3,4 \%$ \\
\hline 5 & $12 / 01 / 2007$ & Pre & 5 & $0,0 \%$ & $7,2 \%$ & $91,2 \%$ & $1,6 \%$ \\
\hline 6 & $12 / 01 / 2007$ & Pre & 5 & $0,0 \%$ & $6,2 \%$ & $93,2 \%$ & $0,6 \%$ \\
\hline 7 & $13 / 01 / 2007$ & $\mathrm{Sec}$ & 6 & $0,0 \%$ & $34,9 \%$ & $64,0 \%$ & $1,1 \%$ \\
\hline 8 & \begin{tabular}{|l|}
$13 / 01 / 2007$ \\
\end{tabular} & Pre & 5 & $0,0 \%$ & $10,2 \%$ & $88,2 \%$ & $1,7 \%$ \\
\hline 9 & \begin{tabular}{|l|}
$13 / 01 / 2007$ \\
\end{tabular} & $\mathrm{Pr}$ & 5 & $0,0 \%$ & $6,5 \%$ & $92,7 \%$ & $0,8 \%$ \\
\hline 10 & $14 / 01 / 2007$ & Not & 10 & $0,0 \%$ & $296 \%$ & $0,0 \%$ & $0,4 \%$ \\
\hline 11 & $15 / 01 / 2007$ & Not & 10 & $0,0 \%$ & $98.4 \%$ & $0,0 \%$ & $1,6 \%$ \\
\hline 12 & $16 / 01 / 2007$ & DEP & 1 & $100,0 \%$ & $0,0 \%$ & $0,0 \%$ & $0,0 \%$ \\
\hline
\end{tabular}

BP 101: (b)

\begin{tabular}{|c|c|c|c|c|c|c|c|}
\hline \multicolumn{4}{|c|}{ Sequence No. $x x \mathbf{x}$} & \multicolumn{4}{|c|}{$\begin{array}{l}\text { Prediction Variables Forward With } \\
\text { Smoothed Model probas S } \\
\text { Baum-Welch algorithm }\end{array}$} \\
\hline$n^{\circ}$ & DATE & CODE & $\begin{array}{c}\text { Symbolic } \\
\text { Codes }\end{array}$ & s1 & S2 & s3 & S4 \\
\hline 1 & $19 / 06 / 2008$ & GW & 5 & $0,0 \%$ & $0,0 \%$ & $0,0 \%$ & $100,0 \%$ \\
\hline 2 & $19 / 06 / 2006$ & GW & 5 & $0,0 \%$ & $0,0 \%$ & $0,0 \%$ & $100,0 \%$ \\
\hline 3 & $20 / 06 / 2008$ & $\mathrm{~s}$ & 7 & $0,0 \%$ & $0,0 \%$ & $99,9 \%$ & $0,1 \%$ \\
\hline 4 & $20 / 06 / 2008$ & Not & 18 & $0,0 \%$ & $1,8 \%$ & $98,2 \%$ & $0,0 \%$ \\
\hline 5 & $20 / 06 / 2008$ & $\mathrm{~s}$ & 10 & $0,0 \%$ & $4,8 \%$ & \begin{tabular}{|l|l|}
$05,2 \%$ \\
\end{tabular} & $0,0 \%$ \\
\hline 6 & $20 / 06 / 2008$ & $\mathrm{~s}$ & 7 & $0,0 \%$ & $5,4 \%$ & \begin{tabular}{|l|l|}
$94,6 \%$ \\
\end{tabular} & $0,0 \%$ \\
\hline 7 & $20 / 06 / 2008$ & $\mathrm{~s}$ & 7 & $0,0 \%$ & $5,5 \%$ & $94,5 \%$ & $0,0 \%$ \\
\hline 8 & \begin{tabular}{|l}
$20 / 06 / 2008$ \\
\end{tabular} & $\frac{5}{5}$ & $\frac{1}{7}$ & $0,0 \%$ & $5,5 \%$ & \begin{tabular}{|l}
$4,50 \%$ \\
$94,5 \%$
\end{tabular} & $0,0 \%$ \\
\hline 9 & $20 / 06 / 2008$ & LC & 1 & $0,0 \%$ & $12,1 \%$ & $83.1 \%$ & $4,8 \%$ \\
\hline 10 & \begin{tabular}{|l|l}
$21 / 06 / 2008$ \\
\end{tabular} & s & 7 & $0.0 \%$ & $6,8 \%$ & \begin{tabular}{|l|l|}
$93.2 \%$ \\
\end{tabular} & $0.0 \%$ \\
\hline 11 & \begin{tabular}{|l}
$21 / 06 / 2008$ \\
\end{tabular} & $\mathrm{CL}$ & 2 & $0,0 \%$ & $0,4 \%$ & $1,4 \%$ & $98.1 \%$ \\
\hline 12 & $\mid \frac{21 / 100 / 2000}{21 / 06 / 2008}$ & No & 19 & $0,0 \%$ & $0,0 \%$ & $0,0 \%$ & $100,0 \%$ \\
\hline 13 & $21 / 06 / 2008$ & No & 19 & $0,0 \%$ & $0,0 \%$ & $0,0 \%$ & $100,0 \%$ \\
\hline 14 & $21 / 06 / 2008$ & No & 19 & $0,0 \%$ & $0.0 \%$ & $0.0 \%$ & $100,0 \%$ \\
\hline$\frac{14}{15}$ & $\frac{21 / 106 / 2008}{21 / 06 / 2008}$ & No & $\frac{19}{19}$ & $0,0 \%$ & $0,0 \%$ & $0.0 \%$ & $\begin{array}{l}100,0 \% \\
100 \%\end{array}$ \\
\hline 16 & $\mid 22 / 06 / 4$ & GW & 5 & $0,0 \%$ & $0,0 \%$ & $0,0 \%$ & $100,0 \%$ \\
\hline 17 & $22 / 06 /$ & s & 7 & $0,0 \%$ & 0,0 & $99,9 \%$ & $0,1 \%$ \\
\hline 18 & $22106 /$ & MP & 11 & $0,0 \%$ & $920 \%$ & $0.4 \%$ & $7,6 \%$ \\
\hline 19 & 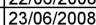 & $\mathrm{MP}$ & 11 & $0,0 \%$ & $9799 \%$ & $0,0 \%$ & $2,1 \%$ \\
\hline 20 & \begin{tabular}{|l}
$23 / 06 / 2008$ \\
\end{tabular} & Rep & 15 & & $0,0 \%$ & $0,0 \%$ & $0,0 \%$ \\
\hline
\end{tabular}
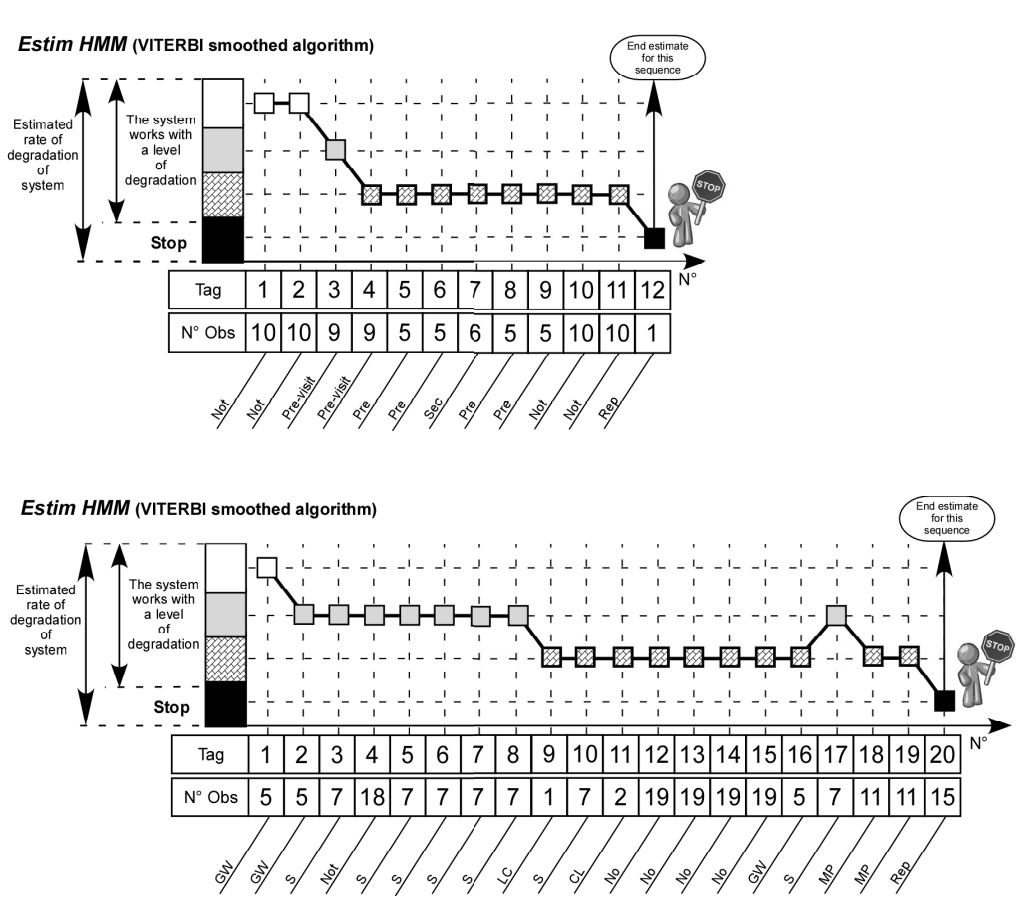

Fig. 15 Sample tests

Table 7 Failure probability for S2 state “on” - Volumetric balance (2007 database)

Volumetric balance: (a)

\begin{tabular}{|c|c|c|c|c|c|c|c|c|c|c|c|}
\hline \multirow{2}{*}{$\begin{array}{l}\text { Prediction } \\
\text { Viterbi } \\
\text { smoothed }\end{array}$} & at +1 day & at +2 days & at +3 days & at +4 days & at +5 days & at +6 days & at +7 days & at +8 days & at +9 days & at +10 days & at +11 days \\
\hline & $0,0 \%$ & $9,1 \%$ & $18,2 \%$ & $27,3 \%$ & $36,4 \%$ & $36,4 \%$ & $45,5 \%$ & $45,5 \%$ & $54,5 \%$ & $63,6 \%$ & $100,0 \%$ \\
\hline \multirow{2}{*}{$\begin{array}{c}\text { Prediction Variables } \\
\text { Forward With } \\
\text { Smoothed Model probas }\end{array}$} & at +1 day & at +2 days & at +3 days & at +4 days & at +5 days & at +6 days & at +7 days & at +8 days & at +9 days & at +10 days & at +11 days \\
\hline & $28,6 \%$ & $71,4 \%$ & $85,7 \%$ & $85,7 \%$ & $85,7 \%$ & $85,7 \%$ & $100 \%$ & $100 \%$ & $100 \%$ & $100 \%$ & $100 \%$ \\
\hline
\end{tabular}


Table 8 Failure probability for S2 state “on" - BP Wheel (2008 database)

Foundry: (b)

\begin{tabular}{|c|c|c|c|c|c|}
\hline $\begin{array}{c}\text { Prediction } \\
\text { Viterbi } \\
\text { smoothed }\end{array}$ & at +1 day & at +2 days & at +3 days & at +4 days & at +5 days \\
\cline { 2 - 6 } & $12,5 \%$ & $37,5 \%$ & $50 \%$ & $62,5 \%$ & $100 \%$ \\
\hline $\begin{array}{c}\text { Prediction Variables } \\
\text { Forward With } \\
\text { Smoothed Model probas }\end{array}$ & at +1 day & at +2 days & at +3 days & at +4 days & at +5 days \\
\hline
\end{tabular}

Explanation of Table 7 and Table 8: Proposed model always provides S1 state when a default occurs, but it is too late, because default occurs ... So to evaluate our method, we sum up occurrences of "S2 state at x days" before default occurs. For example, in Table 8 with forward variables at +2 days, $71,4 \%$ mean that the probability that a default occurs in two days is $71,4 \%$. This supposes that "S2 state" always precedes "S1 state".

In one hand, we show with these tables that learning with segmental k-means algorithm and testing with Viterbi algorithm, is not efficient to give good failure prediction (in both cases of volumetric balance and BP Wheel). S2 state is detected too early which cannot provide our goal.

On the other hand, Forward variables with Baum-Welch algorithm provide good results for default predictions. We can provide efficient predictions for S2 state, under statistical information (5.38 days). Fig. 16 (a) and (b) show additional information that is available to the expert. Once the $\mathrm{S} 2$ state is detected, the expert should react.
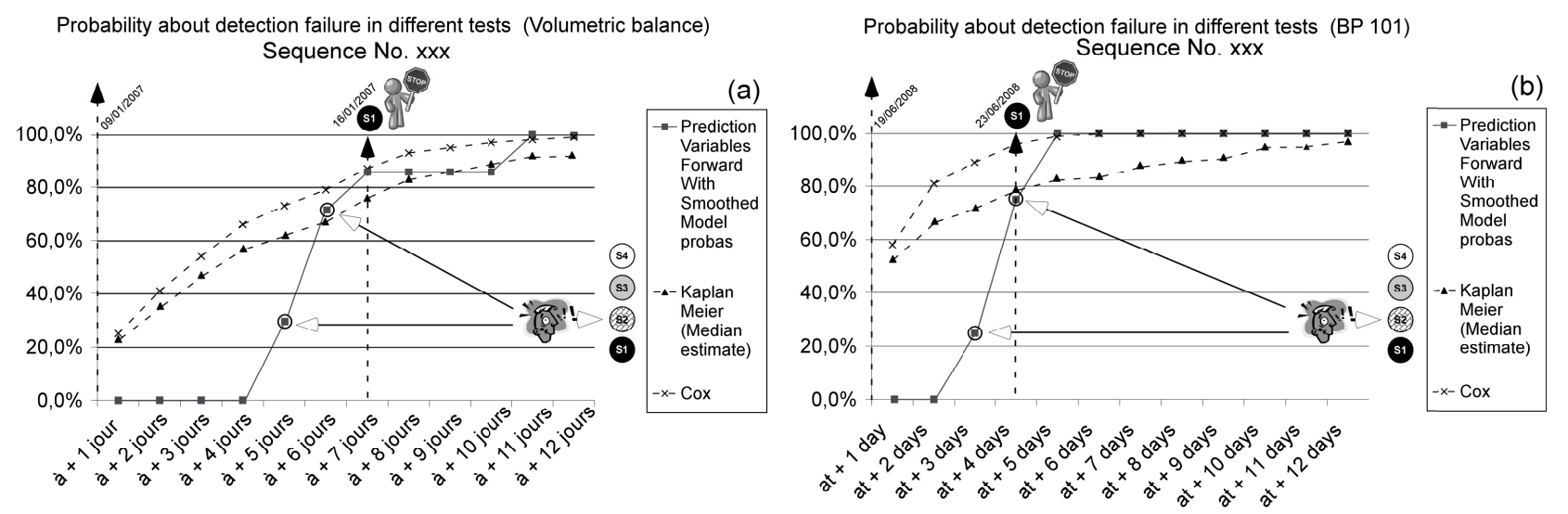

Fig. 16 Triggering of "S2 state"

\section{CONCLUSION AND FUTURE WORKS}

In this paper, after an overview of different maintenance approaches, we presented a nonparametric and semiparametric evaluation of system state: Kaplan-Meier and Cox. Our approach based on HMM was then developed. Tests of these different methods were performed onto two real situations: volumetric balance and BP Wheel. Our approach shows that all results provided by this study could provide some help to expert decisions. Results show that our "decision support" provides a good estimation of repair probability when events (observations) are available.

Without events (observations) HMM method is less useful, then nonparametric and semi parametric laws could be used on foreground (Fig. 17). We also show that the expert with such a tool can try to qualify maintenance activities. Tests were carried out offline, so we cannot assess the effects of scheduling dynamically maintenance 
activities. We will soon sign a contract with the foundry industrial group, for the On line implementation of these methods. Before considering implementation in real-time situation, we will explore possibilities of process simulation for which we could apply dynamic scheduling of maintenance.

Initial analysis of events provided by manufacturers, allowed them to consolidate their knowledge onto effects of specific maintenance activities (indicator can provide, in some cases, information about maintenance activities "quality"). For example, is a maintenance activity efficient or not or neutral for the system?

In future works, we wish to evaluate performances of the method on simulated data and perfectly controlled. This assessment will better evaluate performances of this availability indicator. The authors would like to thank the anonymous reviewers for their helpful comments and advices which contribute much to the improvements of this paper.

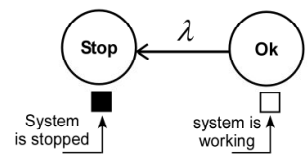

a)

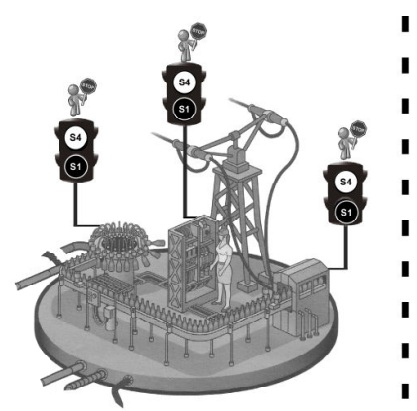

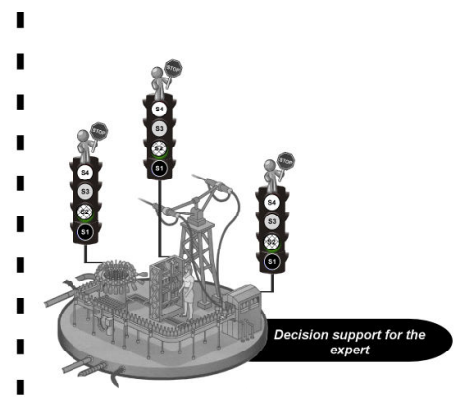

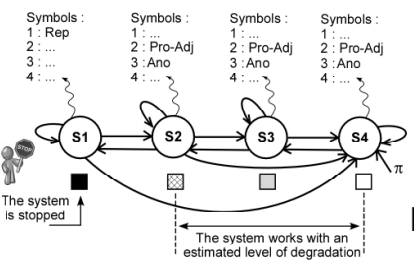

Fig. 17 Kaplan-Meier \& Cox vs HMM

\section{REFERENCES}

N. F. E. N. 13-306, maintenance terms, 2001.

C. E. I. 812, Procedures for performing a failure modes and effects analysis, 1985.

N. F. E. N. 13306X60-319, Reliability, Availability and Maintainability, 2001.

Aupetit S., Monmarché N. and Slimane M., Hidden Markov models training using population based metaheuristics, in Advances in Metaheuristics for Hard Optimization, Natural Computing Series, Siarry P. and Michalewicz Z., Springer-Verlag, 2008, 415-438.

Ayyub B. and Mccuen R., Probability, Statistics \& Reliability for engineers, CRC Press, New York, 1997.

Basile O., Dehombreux P. and Riane F., Identification of reliability models for non repairable and repairable systems with small samples, Advances in Maintenance and Modeling, Simulation and Intelligent Monitoring of Degradation, Proceeding of IMS'2004, Arles, 2004.

Baum L.E., An inequality and associated maximization technique in statistical estimation for probabilistic functions of a markov process, Inequalities, 1972, 3, 1-8.

Baxter L.A., Kijima M. and Tortorella M., A point process model for the reliability of a maintained system subject to general repair, Communications in Statistics - Stochastic Models, 1996, 12, 37-65.

Bérenguer C., On the mathematical condition-based maintenance modelling for continuously deteriorating systems, International Journal of Materials \& Structural Reliability, 2008, 6(2), 133-151.

Bérenguer C., Châtelet E., Langeron Y. and Despujols A., Modeling and Simulation of Maintenance Strategies using Stochastic Petri Nets, Proceedings of MMR 2004, Mathematical Methods in Reliability, Santa Fe, USA, 2004. Bertholon H., Bousquet N. and Celeux G., An alternative competing risk model to the Weibull distribution for modelling aging in lifetime data analysis, Lifetime Data Analysis, 2006, 12(4), 481-504.

Birolini A., Quality and reliability of technical systems, Edition Springer, 1994. 
Bitouzé D., Laurent B. and Massart P., A Dvoretzky-Kiefer-Wolfowitz type inequality for the Kaplan-Meier estimator, Annales de l'Institut Henri Poincaré, 1999, 35, 735-763.

Bouvard F., Artus S., Bérenguer C. and Cocquempot V., Maintenance Cost Study for Deteriorating Systems:Age-Replacement Policy vs Condition-Based Maintenance Policy, International Journal of Materials \& Structural Reliability, 2008, 6(2), 167-179.

Breslow N., Applications to clinical trials of multiple regression models for censored survival data, The Scientific Meeting of the Committee on Controlled Therapeutic Trials of the U.I.C.C, April, 1973.

Brookmeyer R. and Crowley J., A confidence interval for the median survival time, Biometrika, 1985, 72(3), 619625.

Castanier B., Bérenguer C. and Grall A., A sequential condition-based repair/replacement policy with nonperiodic inspections for a system subject to continuous wear, Applied Stochastic Models in Business and Industry, 2003, 19(4), 327-347.

Chandler A.D.J.R., Stratégie et structures de l'entreprise, Editions d'organisation, Paris, 1989.

Cheuk-Kit W. and Eng Wie T., Survival over 5 years in the initial hospital survivors with acute coronary syndrome: a comparison between a community hospital and a tertiary hospital in New Zealand, Journal of the New Zealand Medical Association, 2007, 120(1261).

Commission of the European communities, On the assessment and management of flood risks, 2007/60/EC, 2007.

Commission of the European communities, Prevention, preparedness and response to terrorist attacks, $\operatorname{COM}(2004) 698$ final, 2004.

Cotaina N., Matos F., Chabrol J., Djeapragache D., Prete P., Carretero J., García F., Perez M., Pena J.M. and Perez J.M., Study of existing reliability centered maintenance (RCM) approaches used in different industries, TR Number FIM/110.1/DATSI/00, Facultad de Informatica de Madrid, 2000.

\section{4, 187-220.}

Deloux E., Castanier B. and Bérenguer C., Maintenance policy for a deteriorating system evolving in a stressful environment, Proceedings of the Institution of Mechanical Engineers, Part O: Journal of Risk and Reliability, Volume 222, Number 4 / 2008, pp. 613-622, 2008.

Dieulle L., Bérenguer C., Grall A. and Roussignol M., Sequential condition based maintenance scheduling for a deteriorating system, European Journal of Operational Research, 2003, 150, 451-461.

Doyen L. and Gaudoin O., Classes of imperfect repair models based on reduction of failure intensity or virtual age, Reliability Engeniering and System Safety,2004, 84(1:45), 45-56.

Ebeling C.E., Introduction to Reliability and Maintainability Engineering, Mc Graw-Hill Series, 1997.

Hastings N.A.J., The repair limit replacement method, Opl. Res. 1969, Q. 20, 337-349.

Hoang P., Handbook of Reliability Engineering, Springer, 2003.

Hopp W.J. and Wu S.C., Multiaction maintenance under Markovian deterioration and incomplete state information, Naval Research Logistics, 1998, 447-462.

Innal F., Dutuit Y., Rauzy A. and Signoret J.P., New insight into PFDavg and PFH, Safety Users Group, 2008. New York, 2002.

Kijima M., Some results for repairable systems with general repair, Journal of Applied Probability, 1989, 26, 89102. of the Kaplan-Meier estimator, Proba. Theory Related Fields, 1989, 80, 461-473.

Meier-Hirmer C., G Riboulet G., Sourget F. and Roussignol M., Maintenance optimization for a system with a gamma deterioration process and intervention delay: application to track maintenance, Proceedings of the Institution of Mechanical Engineers, Part O: Journal of Risk and Reliability, 2009, 223(3), 189-198. Moubray J., Reliability Centered Maintenance, New York, Industrial Press, $2^{\text {nd }}$ edition, 1997. Muth E.J., An optimal decision rule for repair versus replacement, IEEE Trans. on Reliability, 1997, R-26, 179181.

Phelps R.I., Replacement policies under minimal repair, J. Opl. Res. Soc., 1981, 32, 549-554. process industry, Risk Anal, 2003, 23(3), 445-59. 
Rabiner L.R., A tutorial on hidden Markov models and selected applications in speech recognition, Proceeding of the IEEE, 1989, 77, 257-286.

41 Simeu-Abazi Z. and Sassine C., Maintenance integration in manufacturing systems by using stochastic Petri nets, International Journal of Production Research, 1999, 37, 3927-3940.

42 Soro I-W., Nourelfath M. and Aït-Kadi D., Performance Evaluation of multi-state degraded systems with minimal repairs and imperfect maintenance, Reliability Engineering and System Safety, 2010, 65-69. Thietart R.A. and Martinet A.C., Stratégies : actualité et futurs de la recherche, Edition Vuibert / FNEGE, Paris, 2001.

44 Valdez-Florez C. and Feldman R.M., A survey of preventive maintenance models for stochastically deteriorating single-unit systems, Naval Research Logistics, 1989, 36, 419-446.

45 Viterbi A.J., Error bounds for convolutional codes and asymptotically optimum decoding algorithm, IEEE Trans. on Information Theory, 1967, 13, 260-269.

46 Vrignat P., Avila M., Duculty F. and Kratz F., Towards a maintenance and servicing indicator, Advances in Production Management Systems (APMS), IFIP WG 5.7, 2009.

47 Vrignat P., Avila M., Duculty F. and Kratz F., Use of HMM for evaluation of maintenance activities, Int. J. Adaptive and Innovative Systems, 2010, 1(3/4), 216-232.

48 Wang H., A survey of maintenance policies of deteriorating systems, European Journal of Operational Research, 2002, 469-489.

49 Welte T., Deterioration and Maintenance Models for Components in Hydropower Plants, Ph D thesis, Norwegian University of Science and Technology, Department of Productions and Quality Engineering, 2008. Wireman T., Total Productive Maintenance, Industrial Press (Second Edition), 2004. 